\title{
Políticas educacionais e mídia no Brasil: apontamentos sobre o quadro atual
}

\section{Policies to media studies in Brazil: notes about the current situation}

\author{
Juvenal Zanchetta \\ Professor do Departamento de Educação da Unesp-Assis \\ zanchetta@assis.unesp.br
}

\section{Resumo:}

Este artigo descreve algumas das principais estratégias políticas voltadas para a relaçấo entre a escola e a mídia no país. Destacamse ações realizadas pela própria mídia na sua relação com a educação formal; as proposiçóes sobre $\mathrm{o}$ assunto encontradas nos Parâmetros Curriculares Nacionais $(\mathrm{PCN})$; as orientaçôes encontradas nos documentos sobre Gestão Escolar; e algumas das iniciativas concretas realizadas pelos organismos de governo. $\mathrm{O}$ quadro permite observar a distância havida entre as iniciativas gestadas dentro do campo escolar (envolvendo programas curriculares, programas de gestão e a açáo de organismos de governo ligados à área da educação formal) e as propostas externas àquele campo.

Palavras-chave: Escola; Mídia; Política Educacional

\section{Abstract:}

This paper describes some of the key political strategies focused on the relationship between the school and the media in the country. Stand out actions taken by the media in its relationship with the formal education, the proposals on the subject found in the Parâmetros Curriculares Nacionais (PCN), the guidelines found in documents on school management, and some of the concrete initiatives undertaken by the government agencies. The framework allows us to observe the distance between the initiatives managed within the school field (involving curriculum programs, programs management and the action of the government agencies linked to field of formal education) and external proposals outside that field.

Keywords: Education; Media; Political Education 
1 - Até meados dos anos 2000, o projeto estava em desenvolvimento a partir da ação das Secretarias de Estada da Educação do Amazonas, Ceará, Goiás, Maranhão, Pará, Paraíba, Paraná, Pernambuco, Piauí, Rio Grande do Norte, Rio de Janeiro, Rondônia, Roraima, Santa Catarina, São Paulo, Sergipe e Tocantins.

2 - TEIXEIRA, A. A Educação que nos convém. Revista Brasileira de Estudos Pedagógicos, n. 54, abr./ jul. 1954.
Ste artigo traça um panorama das estratégias políticas voltadas para a rela- ção entre a escola e a mídia no país, com a pretensão de esboçar algumas $\mathcal{L}$ das principais linhas de orientação do tema. Por um lado, observamos as ações realizadas pela própria mídia na sua relação com a educação formal. Por outro lado, abordamos quatro flancos da iniciativa, principalmente oficial, voltada ao estudo dos meios de comunicaçáo (MC): a) a proposição sobre o assunto encontrada nos PCN; b) as orientaçóes encontradas nos documentos sobre Gestão Escolar; c) iniciativas concretas realizadas pelos organismos de governo.

Por mídia, compreende-se o conjunto de MC voltados a grandes públicos, sejam eles os meios de "massa", como a televisão e o rádio, sejam os meios interativos, como os suportes amparados pela internet, individualizados, porém potencialmente endereçados a grupos cada vez maiores de leitores. $\mathrm{O}$ termo significa ainda a ação individual ou em rede desses $\mathrm{MC}$, com interesse, ainda que difuso, de firmar posicionamentos frente aos públicos a que se destinam. Nesse sentido, procura-se distinguir a ação dos $\mathrm{MC}$ e a potencialidade das tecnologias de informação e comunicação (TIC), em que pese o fato de nos interessarem também as ações midiáticas propostas com o uso das TIC, ainda que não originadas de grupos empresariais específicos e sim da própria escola ou de organismos diretivos.

A análise de propostas amparadas pela mídia e destinadas à educação formal deve-se à importância assumida pelos MC na arena política nacional, sobretudo nas últimas duas décadas, quando as limitaçóes da escola pública passam a ser observadas a partir de indicadores nacionais e internacionais de avaliação. Segundo Bourdieu: "cinquenta sujeitos inteligentes que conseguem obter cinco minutos na TV para um happening bem-sucedido podem produzir um efeito político comparável ao de meio milhão de manifestantes" (citado por HOBSBAWM, 1995: 314). Nesse sentido, parece decisiva a influência da mídia na formação do imaginário social e político sobre a escola, talvez em grau maior do que a influência dos próprios agentes escolares no mesmo processo.

Em relação à iniciativa oficial, optamos por três frentes representativas da ação dos governos. Os PCN dâo formato concreto ao currículo que se pretende na escola contemporânea. $\mathrm{O}$ tema da gestáo, por seu turno, carrega as proposições políticas maiores para a ação da escola. Para a análise nessa área, observamos o Programa de Capacitação a Distância para Gestores Escolares (Progestão), concebido pelo Conselho Nacional de Secretários de Educação (CONSED) e desenvolvido para a formação de gestores escolares.[1] Observamos também iniciativas em desenvolvimento nos diferentes estados, para verificarmos o perfil de sensibilização para o tema encontrado nessas instâncias centrais na estrutura da educação no país.

\section{HisTóRIA}

Embora impliquem processos formativos semelhantes, escola e mídia seguiram percursos distintos, desde a criação dos estados nacionais, no século 18, quando essas duas instituiçóes consolidam participação na história das sociedades contemporâneas. Anísio Teixeira, na década de 1950, afirmou que o cinema e o rádio conseguiam, mais do que a escola, combater a "cegueira" do analfabetismo, criando oportunidade para que as pessoas pudessem participar do "debate geral" sobre a nação.[2] Mas a escola acabou por fazer uso apenas de elementos isolados da mídia, em geral como pretexto para tratamento de conteúdos de disciplinas específicas - e isso aconteceu apenas muito recentemente. Ao longo do século 20, 
quando o Brasil constitui sua estrutura educacional formal, prevaleceu o aspecto moral: os MC mostravam-se fúteis demais para a obra de formação moral e enciclopédica proposto pelo estatuto da escola brasileira. O próprio Anísio Teixeira já reclamava, naquele mesmo texto dos anos 1950, dos "conteúdos prejudiciais" que o cinema e o rádio despejavam sobre a audiência.

O rádio, o cinema, a televisão e mesmo o jornal impresso, suportes de grande prestígio durante o século 20, ganham algum espaço na escola brasileira apenas a partir dos anos 1980, mais de dois séculos depois da consolidaçáo da imprensa na cultura ocidental. Ainda assim, os MC não chegaram a ser abordados como produtores e divulgadores de informação, mas sim como portadores de textos que poderiam ser adaptados e utilizados na rotina dos currículos regulares. Isso aconteceu, por exemplo, com a entrada do vídeo e da televisão nas escolas, nos anos 1980. O papel desses equipamentos restringiu-se a ilustrar conteúdos curriculares, com a exibição de filmes (adaptações de obras literárias ganharam enorme espaço na escola) ou documentários. O procedimento, em parte, repetese nos dias de hoje, quando o acesso de estudantes a computadores está restrito a softwares oficiais ou então a sítios de informação autorizados.

A história dos $\mathrm{MC}$ no Brasil também não apresenta esforço consistente e continuado para a formação de leitores, exceto em ações isoladas, originadas principalmente de jornais impressos. Os programas de formação ligados a empresas jornalísticas surgem apenas nos anos 1980[3] e mesmo hoje persistem mais em função do marketing das empresas e da perseverança de determinados jornalistas ou grupos do que por conta de uma proposta comum e voltada para a promoção da leitura midiática. Em geral, tais programas promovem a iniciação de estudantes na compreensão dos instrumentos da cultura jornalística (o texto da notícia e da reportagem, além de componentes menos "didatizados", como os elementos de representaçáo de dados meteorológicos, a charge e o projeto gráfico dos jornais, por exemplo). Estima-se em cerca de 70 (dentro de um universo de mais de 600 diários) o número de jornais, em sua maioria mediana em termos de circulação, que patrocinam programas de formação de leitores. As principais revistas de informação jornalística do país também mantêm programas, mais ou menos estruturados, de formação de leitores. Esse exercício, no entanto, é semelhante ao dos jornais: pouco integrado e voltado à construção de dinâmicas próprias de contato com os novos leitores.

Em termos de radiodifusão (incluindo televisão), o quadro também é tímido,[4] com raríssimas iniciativas voltadas à preparação da audiência. No Código Brasileiro de Telecomunicaçôes (Lei federal 4117, de 1962), o tema da educação aparece, e de forma indireta, apenas na referência genérica a supostos abusos à "moral familiar, pública ou aos bons costumes" (artigo 53). No Regulamento dos Serviços de Radiodifusáo (RSR) (1963), embora se explicite que a finalidade da radiodifusão no país é "educativa e cultural" (artigo 30), não há nenhuma orientaçáo concreta quanto a isso.

Como as antecessoras, leis posteriores privilegiaram a questão política e o patrimonialismo envolvido nas concessóes. Alterado em 1983, O RSR incluiu a obrigatoriedade de veiculaçáo de "programas educativos" nas emissoras de radiodifusão (Decreto federal 88.067). Entretanto, a "cota educativa" ficou restrita a menos de $3 \%$ do total de programação (em horário indefinido), sem que se estabelecesse o perfil de conteúdo educativo a ser exibido (insistindo-se, apenas, na ideia de preservação da moral e dos bons costumes).
3 - O pioneiro foi o jornal Zero Hora, de Porto Alegre, com programa iniciado no começo da década de 1980 . O programa estava desativado em meados da década de 2000.

4 - Dois textos de Maria Luiza Belloni ajudam a mapear e a mostrar a timidez do esforço da televisão para a educação formal (e não para a formação do leitor para ler a própria televisão): “A televisão como ferramenta pedagógica na formação de professores" (Revista Educação e Pesquisa, dez. 2003, v.29, n.2); “Ensaio sobre a educação a distância no Brasil" (Revista Educação \& Sociedade, abr. 2002, v.23, n.78). 
Além de vago, o tema da educação, na legislação para os serviços de comunicação, não está relacionado à escola. A iniciativa para tanto seria realizada apenas em 1995, com a criaçáo da TV Escola. Mas o desatrelamento entre comunicação e educação formal no país pode ser visto na dificuldade de consolidação da TV Escola no cenário educacional brasileiro: mesmo próximo da dinâmica curricular regular, esse canal estatal esbarra na falta de experiência cultural dos agentes (de produtores a professores) em relação a esse tipo de "ferramenta pedagógica”, como afirma Belloni (2003). Por outro lado, iniciativas provenientes da iniciativa privada, como o canal Futura, tendem a buscar formas alternativas de educação, não raro evitando, inclusive, referências ao cenário escolar.

Em décadas recentes, fatores como a popularização e a diversificação dos $\mathrm{MC}$, bem como o esgotamento do modelo de formação enciclopédico (em nome de uma preparação mais pragmática), fizeram com que a educação formal e a comunicação passassem a compartilhar procedimentos: a escola passou a se utilizar mais intensamente de suportes e mensagens midiáticas em sua rotina; veículos de comunicação ou mesmo governos investem esforços para aperfeiçoar estruturas pedagógicas a partir das tecnologias de informação e comunicação (TIC).

Desde o início dos anos 1990, as publicaçóes didáticas popularizaram propostas de trabalho com jornais e revistas. Nos dias de hoje, há coleçôes de livros didáticos, bem como projetos de produçáo e leitura de textos quase completamente compostos por conteúdos veiculados na imprensa. A linguagem jornalística, como referência de registro verbal de prestígio; o texto jornalístico, como modo simples e eficiente de comunicação; a sugestão de dinamismo e de "ponte para o mundo real"; a oportunidade para o debate dos grandes temas sociais; todos esses argumentos justificam a presença dos conteúdos jornalísticos na sala de aula.

A prática de escolarizar gêneros como a notícia, a reportagem, o fotojornalismo, os textos de opiniáo, entre outros expedientes, reproduz a "cultura do fragmento", tão comum na escola, em algumas das características mais problemáticas dessa cultura: o tratamento pontual e isolado de conteúdo, para "treinar" a leitura ou o tratamento da forma pela forma.

\section{A mídia fala da escola}

Em parte devido à timidez das proposiçôes escolares, a mídia, por si mesma, tem exercido funções cada vez mais pronunciadas em termos de "formação escolar". Entre as diversas funçóes desempenhadas por ela em relação à escola, podemos citar algumas, mais evidentes, numa ordem crescente de complexidade:

a) Complemento: diversos suportes póem-se a realizar projetos de auxílio à formação educacional. São exemplos nessa linha desde os cadernos preparatórios para os exames vestibulares, os manuais de redação de jornais e os projetos de conteúdos pedagógicos realizados por grandes veículos de comunicação. Por um lado, são vários os projetos que procuram dialogar mais de perto com os currículos oficiais, oferecendo material para pesquisa e aplicaçáo, além de formarem leitores de textos midiáticos. Como exemplo nessa linha, está a revista Nova Escola (Editora Abril). Por outro lado, tais processos chegam a criar autoridades escolares fora da escola: é o caso de especialistas no uso do registro de linguagem de maior prestígio, por exemplo, que dão receitas em jornais, no rádio e na televisão sobre o que é certo e o que é errado no uso da palavra;

b) Alternativa: trata-se, por exemplo, dos canais educativos e de programas específicos de preparação para diferentes áreas do conhecimento (da língua 
portuguesa à física). A atualidade, a visibilidade e o dinamismo dos suportes midiáticos seriam fatores que os transformariam em agentes privilegiados para o ensino. Encontram-se aqui exemplos como o canal Futura e a TV Escola. Neste âmbito também se inserem as publicaçôes oriundas de jornais e revistas, voltadas ao público escolar. Distinguem-se em relação ao primeiro grupo, por buscarem caminhos mais distanciados do currículo regular;

c) Crítica: a escola, e os organismos públicos responsáveis por ela são questionados por aspectos ligados ao seu desempenho. Nomes como Gilberto Dimenstein e Rubem Alves, como articulistas de MC de prestígio, incluem-se nessa frente. $\mathrm{O}$ primeiro dá visibilidade a experiências de sucesso, na área da educação, suscitando uma espécie de pacto, envolvendo organismos públicos e privados os mais diversos, em prol da educação. A iniciativa privada assumiria papéis mais decisivos no processo educacional. Já Rubem Alves, defensor de proposta que busca estimular a criatividade e a sensibilidade dos alunos, critica a escola serial, mecânica, tal como ele a vê, nos dias de hoje;

d) Substituição: a ação dos MC ajuda a consolidar políticas públicas. A maior atenção com a Educação Básica, as ênfases na racionalização e no desempenho quantitativo e qualitativo, a ideia de melhoria das competências do professor, por exemplo, foram temas regulares na imprensa nos anos 1990 e transformaram-se em propostas políticas e pedagógicas.[5] Boa parte do discurso político que aponta para a mudança do perfil da ação estatal para a educaçáo (de um Estado educador a um Estado supervisor e avaliador) passa pelas páginas dos principais jornais e revistas. $\mathrm{O}$ contínuo ranqueamento de escolas, cidades e Estados, com a discussáo centrada nas razóes para o sucesso e o planejamento de desempenhos futuros, absorve boa parte do espaço destinado pela imprensa à educação.

Por um lado, a maior atenção da mídia pela educação contribuiu de forma decisiva para colocar o tema da educação escolar na agenda política, acelerando o processo de revisão de seu papel. Por outro, essa exposição está menos preocupada em observar a escola, em suas práticas cotidianas, exceto em termos de soluçóes exitosas para o desempenho de alunos.

\section{Currículo E mídia}

Os PCN não destacam o tema mídia. Tanto no Ensino Fundamental quanto no Ensino Médio trata-se apenas dos gêneros textuais comuns nos MC, em exercícios localizados ao longo do percurso da disciplina de Língua Portuguesa. Interessa mais de perto aos PCN os sentidos da codificação técnica empregada nesses suportes, algo que levaria à leitura crítica desses meios. Importante frisar que os PCN são documentos produzidos há mais de uma década e não dão conta da diversidade tecnológica e de informaçáo propiciada pela rede web nos dias de hoje. A análise de uma questão de fundo que perpassa os documentos curriculares também pode ajudar a confirmar esse tratamento isolado que se confere aos meios e mensagens midiáticas.

O saber instrumental ou o "saber fazer" está na base do Exame Nacional do Ensino Médio (ENEM), uma das iniciativas sinalizadoras da perspectiva educacional do país, por sua vez em sintonia com a proposta do Programme for International Student Assessment (PISA), do qual o Brasil participa. O referencial que sustenta a prova do ENEM materializa a proposta do construtivismo em suas linhas contemporâneas, como também define, para o cenário educacional
5 - Ricardo Filho salienta, por exemplo, como tais características, inspiradas em organismos multinacionais, foram discutidas a partir das páginas de revistas de informação como a Veja - e não a partir de negociação com os meios educacionais propriamente ditos (RICARDO FILHO, G. A boa escola no discurso da mídia. São Paulo: UNESP, 2005). 
6 - A difusão ocorre a partir de diferentes possibilidades havidas entre os meios de comunicação: pela ação em rede; por influências diversas de uns agentes sobre outros; pela simples repercussão de eventos; por sobreposição da ação de um meio sobre outro; pela ação isolada etc.

7 - Por quadros de conhecimentos, tomamos, por exemplo, noções como aquelas relacionadas a cadeias alimentares, à economia de um município, estado ou país, ao contexto em que se inscreve uma obra literária (autor, contexto de produção do texto, gênero, filiação estética e assim por diante). brasileiro, o perfil das competências e habilidades estimuladas nos alunos, algo que acaba sendo replicado nos sistemas estaduais de ensino.

Há obstáculos para a leitura de processos midiáticos sob o ponto de vista do construtivismo. Tais processos envolvem não apenas a percepção das características de cada suporte, mas ainda os traços tipificadores de suas mensagens, as perspectivas de recepção, as ações realizadas para a difusão de conteúdos,[6] os contextos de produção e de leitura, o jogo de pressóes políticas e econômicas. Além de diversos, esses aspectos não são fixos: passam por rearranjos, em razão da mobilidade da produçáo e da expectativa dos sujeitos leitores. Os documentos de orientação oficial, por outro lado, estão centrados na ideia de avaliação e observam certo quantum de conhecimento acerca de cenários, códigos e processos, mais ou menos delimitáveis, desenvolvidos em currículos pré-concebidos, materializados num dado momento.

As competências e habilidades estabelecidas como prioritárias para a escola básica vão até o limite dos textos específicos em que se inscrevem as mensagens ou, quando muito, a quadros de conhecimentos,[7] já delineados no currículo formal, dificultando também em termos programáticos a leitura de processos midiáticos. As competências que se aproximariam do trabalho com a mídia são as seguintes:

\section{Dominar a norma culta da Língua Portuguesa e fazer uso das linguagens matemática, artística e científica. II. Construir e aplicar conceitos das várias áreas do co- nhecimento para a compreensão de fenômenos naturais, de processos histórico-geográficos, da produção tecno- lógica e das manifestaçóes artísticas. \\ III. Selecionar, organizar, relacionar, interpretar dados e informaçóes, representados de diferentes formas, para to- mar decisóes e enfrentar situaçóes-problema. (INEP, 2002)}

Os códigos midiáticos não se limitam à linguagem verbal e, na grande maioria dos veículos, a linguagem de maior prestígio ou a "linguagem culta" é apenas uma referência. Por outro lado, o funcionamento da mídia implica engendrar questôes históricas e políticas não redutíveis aos limites de algumas semanas de aulas. A seleção, organização e associação de dados e informações, em termos de relacionamento do estudante ou mesmo do professor com a mídia, servem mais à ideia de consumo do que propriamente ao processo de leitura.

As habilidades correspondentes às competências preconizadas para a educação básica também mantêm certa distância de uma perspectiva de trabalho que envolva questôes políticas e ideológicas. Entre as vinte e uma habilidades sugeridas, quatro delas poderiam voltar-se à leitura relacionada à mídia:

- Com base em um texto, analisar as funçóes da linguagem, identificar marcas de variantes linguísticas de natureza sociocultural, regional, de registro ou de estilo, e explorar as relaçóes entre as linguagens coloquial e formal.

- Confrontar interpretaçóes diversas de situações ou fatos de natureza histórico-geográfica, técnico-científica, artístico-cultural ou do cotidiano, comparando diferentes 
pontos de vista, identificando os pressupostos de cada interpretação e analisando a validade dos argumentos utilizados.

- Comparar processos de formação socioeconômica, relacionando-os com seu contexto histórico e geográfico.

- Dado um conjunto de informaçóes sobre uma realidade histórico-geográfica, contextualizar e ordenar os eventos registrados, compreendendo a importância dos fatores sociais, econômicos, políticos ou culturais. (INEP, 2002)

A primeira das habilidades liga-se a operaçóes de ordem estrutural com a linguagem verbal. As demais estão direcionadas ao ensino de geografia. Poderiam elas abarcar o universo da mídia, mas o fariam também de modo parcial.

O conhecimento, sob a perspectiva construtivista, mostra-se de maneira, se não acabada, ao menos estável. Pressupóe-se certa organicidade nos processos que se desenvolvem pelo e à volta do homem. No caso da análise midiática, por outro lado, existe a necessidade de abordagem ideológica dos textos: há o traço da política, das tensões inerentes às diversas percepçôes acerca dos papéis exercidos pelos meios de comunicação; as individualidades; e as relaçóes coletivas que de algum modo interferem na recepção. Essa análise mostra-se, portanto, instável diante dos conteúdos vistos sob o prisma construtivista, que aborda a ruptura a partir de um ângulo que diminui o papel do conflito. (MIRANDA, 1995)

Além da ideologia, os traços sensoriais e emotivos inerentes à produção midiática também parecem escapar da abordagem pedagógica predominante. Associada ao consumo imediato, grande parte dos meios explora de forma intensa a componente sensorial, que deixa de ligar-se apenas ao aspecto físico dos suportes, para tornar-se instrumento que interfere e modifica a significaçáo das mensagens. O projeto gráfico dos meios impressos e audiovisuais, a plasticidade e a dinâmica da disposição das informaçóes estáo entre os elementos que valorizam a possibilidade de atrair o leitor, mas também para, de certo modo, conduzir, o quanto possível, sua percepção. Os códigos de postura e de vestimenta, bem como os efeitos sonoros náo são meros adereços em um telejornal: ajudam a dar credibilidade às informaçôes e a auxiliar na hierarquização de valor entre as informaçôes postas. No jornal impresso, a disposição de uma matéria em página determinada já configura, por si, elemento hierarquizador.

Do mesmo modo, o aspecto emotivo atravessa grande parte da produção midiática. Em termos de jornais e telejornais, além do sensacionalismo próprio da natureza da imprensa, entre as marcas centradas na obtenção do efeito de sensibilização do leitor ou espectador estáo a organizaçáo textual (perfil de linguagem e oposiçôes, por exemplo), a teatralização (ou, no caso do jornal impresso, a escolha de determinadas ilustraçóes e títulos, suas dimensóes e proximidade com outros textos), a tipificação (com a escolha de personagens ou de perfis, ou ainda de cenários que melhor se enquadrem na perspectiva de efeito que se quer promover), o próprio suspense estimulado pela primeira página de jornal ou pela escalada de um telejornal.

Os documentos, enfim, remetem a uma noção de aprendizado do aluno, que, além de genérica, estabelece um conjunto de competências e habilidades pouco afeita ao tratamento da mídia, seja porque não há espaço para o contato 
8 - Total de nove cadernos didáticos, que servem de referência para a realização do curso. entre a escola e os MC, seja porque a perspectiva de aprendizagem não leva em conta a complexidade do processo midiático.

\section{Gestấo E Mídia}

Nos Cadernos do Progestão,[8] a relação entre mídia e escola aparece apenas no módulo I e diz respeito à participação de novas tecnologias e dos meios midiáticos na formação dos estudantes:

[...] os conhecimentos sistematizados não estão mais reunidos unicamente em bibliotecas, nem o acesso a eles se dá apenas nas salas de aula. Devido aos avanços tecnológicos e referentes à informação no mundo contemporâneo, o conhecimento circula em complexas redes, sendo veiculado náo apenas pelos meios tradicionais de comunicação (rádio, jornais, revistas, televisão etc.) como também pelo computador e, sobretudo, pela internet. Pensar a escola e sua função social nesse novo contexto significa pensar também sua relação com esses equipamentos e meios de comunicação. (MACHADO, 2001: 48)

A ênfase do documento está na articulação entre a função social da escola e as especificidades e demandas da comunidade, para ajudar o aluno a integrar-se na sociedade, num ponto de vista mais abrangente, ou para auxiliá-lo na entrada no mercado de trabalho, numa ótica mais localizada.

O Progestão baseia-se na perspectiva de que a cultura escolar é construída pela própria escola, com certa independência em relaçáo ao mundo externo. Entre os diversos amparos tomados pela escola, autores como Chervel (1990) e Julia (2001) são emblemáticos, sobretudo porque propóem a escola como campo específico onde predominam costumes e práticas também específicas, centradas mais na própria rotina escolar e não nas proposições (e pressões) externas, de ordem política, científica, cultural etc. Nessa perspectiva, o enfoque não está na sugestão de escola como consequência de certo consenso social - e, portanto, marcada pelas circunstâncias de seu tempo - e sim na ideia de que a escola tem identidade própria suficiente para intervir na sociedade de modo a transformá-la. O modo como Chervel é citado no Progestão é elucidativo dessa autossuficiência:

Chervel afirma que até hoje esse poder criativo do sistema escolar é insuficientemente valorizado pelas pessoas em geral, e que talvez por isso náo se tenha percebido com clareza o duplo papel da escola: o de "formar não somente indivíduos, mas também uma cultura que vem por sua vez penetrar, moldar, modificar a cultura da sociedade global". (CHERVEL, 1990, citado por MACHADO, 2001: 106) 
Essa ótica explica o fato de que as únicas instâncias externas à escola tratadas no Progestão sejam a família do aluno e a comunidade que circunda o espaço escolar. O resultado é um conjunto de sugestôes endógeno, que dá pouca atenção a agentes externos que não aqueles necessários ao imediato cotidiano escolar. Curiosamente, ao serem induzidas à intensa revisão das próprias práticas, as escolas tendem ao hiperdimensionamento da práxis em detrimento de questôes políticas: o esforço sempre provisório de adequação da escola acaba por implicar não a negociaçáo com o mundo exterior, mas sim a construçáo ininterrupta de um projeto voltado para o próprio cotidiano da escola.

Os aspectos mencionados insistem no isolamento e, portanto, no distanciamento em relação a outros setores, como a imprensa, a televisão comercial, os veículos de propaganda, as organizaçóes não governamentais e os próprios governos, mesmo que tal opçáo custe à escola a sua fragilização crescente no jogo de pressóes políticas. O resultado tende a ser um abismo entre a escola, por si mesma, e aquilo que se fala dela na mídia, com franca vantagem (em termos de visibilidade) para os discursos externos.

\section{ESTAdos dA FEDERAÇão E PROPOSTAS PARA A MÍdia}

A análise das propostas estaduais deu-se por meio de consulta aos sítios oficiais das secretarias da educação, observando-se os documentos curriculares e os programas ali dispostos. É certo que os sítios oficiais náo abarcam a totalidade da açáo desenvolvida no âmbito de cada secretaria. Entretanto, também é certo que os programas e ações destacadas nos portais alcançaram nível de consistência e consenso nos próprios governos, de modo a transformar-se em estratégias que servem como alternativa de trabalho (para a comunidade escolar) e também de propaganda (para o público externo).

Uma visada geral permite as seguintes constatações: a) a adaptação das escolas ao uso das TIC, para informatização dos serviços e para operação de computadores por alunos (algo que se apresenta como objetivo na maioria dos estados) e pela comunidade do entorno da escola (como propóe o projeto "Comunidade Digital", desenvolvido no Mato Grosso do Sul); b) o tratamento da mídia materializado a partir do estudo de gêneros textuais comuns nos $\mathrm{MC}$, em especial nos jornais impressos, mas também destacando, em alguns casos, gêneros próprios às tecnologias que se utilizam da rede web (blog, chat, fotoblog e torpedos, entre outros), como acontece no Paraná.

Além de conteúdos curriculares, serviços informatizados e laboratórios de informática, ao menos dois estados, Santa Catarina (pioneiro) e São Paulo, oferecem o jornal impresso como recurso pedagógico adicional. Em São Paulo, dentro do projeto Sala de Leitura, como recurso pedagógico, as escolas recebem exemplares de jornais e revistas.

Ainda em fase inicial, Bahia (com o projeto 'Cinemaçáo', voltado ao uso de aparelhos celulares para produção de vídeos de curta duração), Mato Grosso, Pará e São Paulo (com a criação de miniestações de rádio) buscam alternativas para o uso pedagógico de recursos tecnológicos midiáticos. Investe-se no domínio quanto ao uso dos $\mathrm{MC}$, para a produção da informação pelos estudantes, fazendo-se dessas práticas terreno para a expressão, 
9 - Desenvolvida pelo Núcleo de Comunicação e Educação, da Escola de Comunicações e Artes da Universidade de São Paulo, em linhas gerais, a Educomunicação busca aproximar professores e estudantes de vivências típicas dos meios de comunicação, com o intuito de fazer com que os indivíduos se apropriem e se tornem sujeitos dessas linguagens. compreensão da dinâmica midiática e integração social, em acordo com a Educomunicação,[9] principal tendência de estudos que envolvem comunicação e educação no país.

Enfim, a busca nos sítios oficiais das secretarias teve o objetivo de verificar apenas as linhas gerais do trabalho desenvolvido em relação ao grande tema ora destacado. Náo se abarcam aqui propostas experimentais desenvolvidas em escala piloto, nem sequer iniciativas regionais ou locais.

\section{ConsideraÇão Final}

Ao buscar pontos de contato com a política educacional vigente, destacando a potencialidade da Educomunicação para a formação de sujeitos autônomos dentro da escola, Soares faz a seguinte observação:

\begin{abstract}
... são poucos os pensadores da área da educação que se sentem à vontade em aproximar estas expectativas de valores ao universo representado pela comunicação, suas linguagens e tecnologias. É como se, no imaginário destes teóricos, os dois mundos - o da educação e o da comunicação - não se tocassem ou, quando muito, permanecessem no âmbito da didática (a comunicação como recurso esporadicamente usado pelo professor). (SOARES, 2011: 81)
\end{abstract}

Ao longo deste texto, mesmo de maneira introdutória, procuramos discutir fatores políticos que explicam essa suposta distância entre a comunicação e a educação formal no país. De um lado, iniciativas midiáticas cada vez mais investem na fixação de modelos descolados da história da escola brasileira. De outro, as iniciativas escolares ainda percebem o tema da educação para a mídia como um elemento secundário, quando muito passível de conversão em tópico curricular. Ao fundo, uma história de regulamentação da mídia pouco atenta às relaçóes educacionais aí implicadas.

Nesse cenário em que os vários campos atuam de maneira isolada, aumenta a chance de os sistemas educacionais brasileiros se voltarem decididamente ao aparelhamento das escolas, para estimular habilidades quanto ao uso das tecnologias, posto ser esse o menor denominador comum entre os vários flancos aqui discutidos.

\section{REFERÊNCIAS BIBLIOGRÁFICAS}

BELLONI, M.L. "A televisão como ferramenta pedagógica na formação de professores”. Educação \& Pesquisa, v.29, n.2, São Paulo, jul./dez. 2003.

CHERVEL, A. "História das disciplinas escolares: reflexôes sobre um campo de pesquisa". Teoria \& Educação, n.2, 1990.

HOBSBAWM, E. Era dos Extremos: o Breve Século XX: 1914 - 1991. São Paulo: Companhia das Letras, 1995.

INEP - Instituto Nacional de Estudos Pedagógicos. Exame Nacional do Ensino Médio. Brasília: INEP, 2002.

JULIA, D. "A cultura escolar como objeto histórico". Revista Brasileira de História da Educação, n.1, jan./jun. 2001. 
MACHADO, M.A.M. (coord.). Progestão: Como Articular a Função Social da Escola com as Especificidades e as Demandas da Comunidade? Brasília: CONSED, 2001.

SOARES, I.O. Educomunicação - O Conceito, o Profissional, a Aplicação: Contribuiçóes para a Reforma do Ensino Médio. São Paulo: Paulinas, 2011.

SOARES, I.O. "Educomunicação: um campo de mediações". Comunicação \& Educação. São Paulo, n. 19, set.dez. 2000.

ZANCHETTA, J. "Educaçấo para a mídia: propostas europeias e realidade brasileira”. Revista Educação \& Sociedade, v.30, n. 109, set./dez., 2009. 